\title{
BMJ Open Exposure to low-dose ionising radiation from cardiac catheterisation and risk of cancer: the COCCINELLE study cohort profile
}

\author{
Kossi Dovene Abalo (D) , ${ }^{1}$ Sophie Malekzadeh-Milani, ${ }^{2}$ Sébastien Hascoët, ${ }^{3}$ \\ Serge Dreuil (1) , ${ }^{4}$ Tiphaine Feuillet, ${ }^{5}$ Sarah Cohen, ${ }^{3}$ Claire Dauphin, ${ }^{6}$ \\ Sylvie Di Filippo, ${ }^{7}$ Stéphanie Douchin, ${ }^{8}$ François Godart, ${ }^{9}$ Patrice Guérin, ${ }^{10}$ \\ Pauline Helms, ${ }^{11}$ Clement Karsenty, ${ }^{12}$ Bruno Lefort, ${ }^{13}$ Pierre Mauran, ${ }^{14}$ \\ Caroline Ovaert, ${ }^{15}$ Jean-François Piéchaud, ${ }^{16}$ Jean-Benoît Thambo, ${ }^{17}$ \\ Klervi Leuraud, ${ }^{1}$ Damien Bonnet, ${ }^{2}$ Marie-Odile Bernier, ${ }^{1}$ Estelle Rage ${ }^{1}$
}

To cite: Abalo KD, MalekzadehMilani S, Hascoët S, et al. Exposure to low-dose ionising radiation from cardiac catheterisation and risk of cancer: the COCCINELLE study cohort profile. BMJ Open 2021;11:e048576. doi:10.1136/ bmjopen-2020-048576

- Prepublication history and additional supplemental material for this paper are available online. To view these files, please visit the journal online (http://dx.doi.org/10.1136/ bmjopen-2020-048576)

Received 04 January 2021 Accepted 29 June 2021

Check for updates

(c) Author(s) (or their employer(s)) 2021. Re-use permitted under CC BY-NC. No commercial re-use. See rights and permissions. Published by BMJ.

For numbered affiliations see end of article.

Correspondence to Kossi Dovene Abalo; kossi.abalo@irsn.fr

\section{ABSTRACT}

Purpose The COCCINELLE study is a nationwide retrospective French cohort set up to evaluate the risk of cancer in patients who undergone cardiac catheterisation (CC) procedures for diagnosis or treatment of congenital heart disease during childhood.

Participants Children who undergone CC procedures from 1 January 2000 to 31 December 2013, before the age of 16 in one of the 15 paediatric cardiology departments which perform paediatric CC in mainland France were included. The follow-up started at the date of the first recorded CC procedure until the exit date, that is, the date of death, the date of first cancer diagnosis, the date of the 18th birthday or the 31 December 2015, whichever occurred first. The cohort was linked to the National Childhood Cancer Registry to identify patients diagnosed with cancer and with the French National Directory for the Identification of Natural Persons to retrieve the patients' vital status.

Findings to date A total of 17104 children were included in the cohort and followed for 110335 person-years, with 22227 CC procedures collected. Among the patients, $81.6 \%$ received only one procedure. Fifty-nine cancer cases were observed in the cohort. Standardised incidence ratios (SIRs) were increased for all-cancer (SIR=3.8, 95\% Cl: 2.9 to 4.9), leukaemia (SIR=3.3, $95 \% \mathrm{Cl}: 2.0$ to 5.4 ), lymphoma (SIR=14.9, 95\% Cl: 9.9 to 22.5 ) and solid cancers excluding central nervous system (CNS) tumours ( $\mathrm{SIR}=3.3,95 \% \mathrm{Cl}: 2.0$ to 5.5) compared with the general population.

Future plans Dose reconstruction is currently underway to estimate individual cumulative doses absorbed to relevant organs, including red bone marrow and brain for respectively haematologic disorders and CNS tumours risk estimation. A dose-response analysis will be conducted with consideration to confounding factors such as age at exposure, gender, predisposing factors to cancer and other sources of medical diagnostic low-dose ionising radiation.

\section{Strengths and limitations of this study}

- The study includes a large national sample of children with congenital heart disease who have undergone cardiac catheterisation in France.

- Medical information will be collected from medical records and from the National Health Data System to take into account potential confounding factors such as predisposing conditions to cancer or exposures to other sources of medical diagnostic low-dose ionising radiation.

- The organ doses due to ionising radiation will be estimated for each participant.

Due to the lack of a nationwide cancer registry for adults in France, the cohort will be matched with the National Cancer Institute database built since 2011, to retrieve cancer cases occurring in adulthood in order to assess the association between low-doses ionising radiation exposure and cancer risk throughout the lifetime of the patient.

- The statistical power of the study is limited due to the small size of the study population in view of the low expected cancer risk, however, the ongoing European HARMONIC (Health effects of cArdiac fluoRoscopy and MOderN radlotherapy in paediatrICs) project, aiming to pool seven national cohorts (Belgium, France, Italy, Germany, Norway, Spain and the UK) will increase the statistical power of the analyses.

\section{INTRODUCTION}

Great improvements have been made in medical diagnostic and treatment tools in the recent decades, and modalities using lowdose ionising radiation (LDIR) have been extensively used in medical routine practices. Patients with congenital heart defect (CHD) benefit from better quality of life and longer life expectancy due to improvements 
in cardiac imaging and therapeutic procedures such as cardiac catheterisation (CC). A steady increase in the number of cardiac imaging and therapeutic procedures using LDIR has been observed in patients with CHD from the 1990s. ${ }^{1-3}$ Radiation doses associated with CC procedures are low-to-moderate compared with conventional radiology procedures. However, in some paediatric patients such as transplanted patients and patients with complex heart defects, $\mathrm{CC}$ procedures cumulative radiation doses can exceed 100 millisievert $(\mathrm{mSv}) \cdot{ }^{4-6}$ Furthermore, CHD paediatric patients undergo various forms of other medical X-ray examinations in relation to their condition, including computerized tomography (CT), nuclear medicine and conventional radiology procedures. ${ }^{35-9}$ For these patients, about $60 \%$ of the cumulative radiation dose come from interventional procedures such as $\mathrm{CC}^{5}$ and about $80 \%-95 \%$ come from both interventional and CT procedures. ${ }^{578}$

A 1.6-2 times higher prevalence of cancer has been reported in adult patients with CHD compared with the general population. ${ }^{10}$ Potential explanations to this higher cancer rate include shared genetic or environmental factors, immunosuppression drugs ${ }^{11} 12$ and exposure to medical LDIR procedures. ${ }^{13}$ If ionising radiation is a well-known risk factor of cancer for moderate to high doses, the risk is still debated for doses under 100 $\mathrm{mSv}$, level of doses that can be reached in case of several CC procedures or in case of association between CC and other diagnostic procedures. However, some epidemiological studies have reported an increased cancer risk for doses lower than $50 \mathrm{mSv}$ with risk decreasing with increasing age at exposure. ${ }^{14-16}$ Exposure to medical procedures using LDIR in children is an issue as they have a long life expectancy (therefore more time to develop cancer after exposure to LDIR) and they present a higher sensitivity to LDIR than adults (due to their less mature tissues and organs).${ }^{17-19}$ Data on cancer risk among children and adults with CHD who have undergone cardiac procedures are scarce and only few studies have been published..$^{11220-23}$ Some investigators reported increased risk of cancer among CHD paediatric patients diagnosed and or treated with $\mathrm{CC}^{12}{ }^{12}$ while others did not report any significant findings. ${ }^{23}$ Common limitations to these previous studies were their small size, lack of precise dose assessment and short duration of follow-up.

A nationwide cohort of children and young adults who have undergone diagnostic or therapeutic CC for CHD in childhood, the COCCINELLE (French acronym for COhorte sur le risque de Cancer après Cardiologie INtervention$n E L L E)$ cohort has been established in mainland France. The study aims to assess the risk of cancer in patients with CHD exposed to LDIR during CC procedures. The aim of this study is to describe the cohort and to analyse the cancer occurrence in this population in comparison to the general population.
COHORT DESCRIPTION

\section{Study design}

COCCINELLE is a multicentre cohort study on the risk of cancer in patients with CHD who underwent CC procedures for diagnosis or treatment during childhood. ${ }^{24}$ The study received ethical approval from the French national data protection commission (Commission Nationale de l'Informatique et des Libertés). Retrospective data collection was conducted in 15 hospitals in France based on medical records of CC examinations performed in paediatric cardiology departments.

\section{Patient and public involvement}

Patients and/or the public were not involved in the design, or conduct, or reporting or dissemination plans of this research.

\section{Subject identification and inclusion}

The study participants are patients who underwent their first CC for CHD between 1 January 2000 and 31 December 2013, who were aged $<16$ years at the time of the examination, and who have not been diagnosed with cancer before the first recorded CC procedure.

Medical records for 18906 patients and their 25139 CC procedures were obtained from paediatric cardiology departments. Patients for whom the type of procedure could not be identified from medical records (unknown procedures) and those with unknown gender or those with missing information on dates (birth, death, examination or cancer diagnosis date) were excluded as those with a diagnostic of cancer before the first CC. Then, 17 104 patients with 22227 procedures were included in the cohort (figure 1).

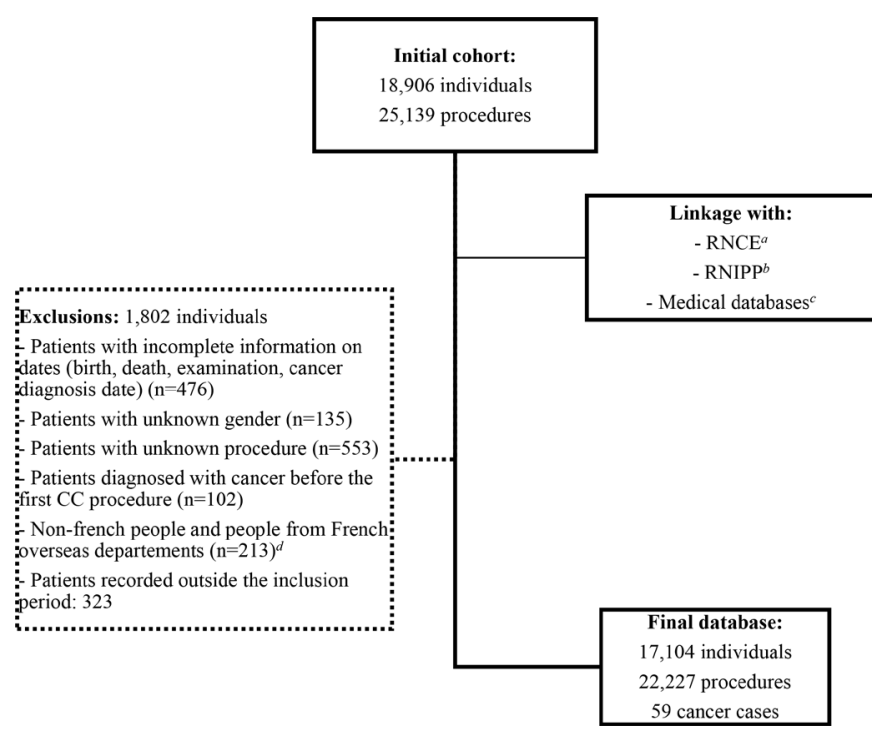

Figure 1 Flow chart of the COCCINELLE cohort constitution. ${ }^{a}$ RNCE, French National Childhood Cancer Registry (Registre National des Cancers de l'Enfant). 'RNIPP, French National Directory for the Identification of Natural Persons. "Medical discharge and reimbursement databases. ${ }^{\mathrm{d}}$ French oversea departments not covered by the RNCE before 2011. CC, cardiac catheterisation. 


\section{Data collection}

Collected data from hospitals include the name, the gender, the place and the date of birth, the identification number, the height and the weight of each patient included in the cohort. The characteristics of the CC procedures such as the date, the type of procedure and the technical details including fluoroscopy time and kerma area product $\left(\mathrm{P}_{\mathrm{KA}}\right)$ when available were also collected.

At each participating hospital, the history of the angiographic systems used during the study period including the type and the brand of the system, the type and the size (in $\mathrm{cm}$ ) of the image detector and the fixed X-ray filtration were collected. In addition, detailed dosimetry reports issued from the system at the end of each CC procedure were collected for a sample of patients. The detailed dosimetry reports include information on primary and secondary angulation, field of view (in $\mathrm{cm}$ ), source-image distance (in $\mathrm{cm}$ ) and tube potential (in $\mathrm{kV})$ ), as well as air kerma and $\mathrm{P}_{\mathrm{KA}}$ per acquisition.

In order to assess a potential confounding effect of the patient's health condition, information on underlying diseases or cancer predisposing factors will be retrieved from various sources including the National Health Data System (Système National des Données de Santé (SNDS)) or from examination of notes fields in procedures' logbooks.

\section{Exposure assessment}

To assess the possible link between the exposure to LDIR from CC procedures and the subsequent occurrence of cancer, individual doses to specific relevant organs, including red bone marrow and brain for, respectively, haematologic disorders (leukaemia and lymphoma) and central nervous system (CNS) cancer risk estimation, will be estimated. First of all, the CC procedures were grouped into a common classification defined by an expert group of cardiologists (DB, SM-M, SH and SC), in order to define families of procedures that are similar. Twelve and three families of procedures were defined, respectively, for therapeutic and diagnostic procedures (online supplemental material S1). LDIR exposure scenarios will be defined based on available detailed dosimetry reports for each family of procedures, for different patient age groups (0-1, 1-5, 5-10, $10-15$ and $\geq 15$ years), and if necessary, for each cardiology department. Based on these exposure scenarios, organ dose computations will be performed with the PCXMC Monte Carlo simulation code (V.2.0, STUK, Helsinki, Finland). The organ dose assessment is underway, consequently at this step of the study, only the number of CC procedures will be considered with regard to the cancer incidence analysis.

\section{Follow-up and outcome}

Follow-up started at the date of the first recorded CC procedure until the exit date that is, the date of death, the date of first cancer diagnosis, the date of the 18th birthday, or the 31st December 2015, whichever occurred first.
Vital status and date of death were obtained through linkage with the French National Directory for the Identification of Natural Persons (RNIPP). Additional information from medical records allowed to complete vital status when the linkage of the cohort with the RNIPP failed to identify a patient ( $25 \%$ of the cohort), as the large majority of the patients were closely followed in the cardiology department for their CHD.

Matching the COCCINELLE cohort with the National Childhood Cancer Registry (Registre National des Cancers de l'Enfant (RNCE)) allowed to identify patients who had been diagnosed with cancer and to obtain the recorded date of diagnosis and the type of cancer. The RNCE has been registering all cancer cases in children less than 15 years old in mainland France, since 1990 for haematologic disorders and since 2000 for solid tumours. ${ }^{25}$ Since 2011, the coverage perimeter of the RNCE has been extended to adolescents under the age of 18 and to residents of French overseas departments. At the time of the linkage, the cancer registry data were available until 31 December 2015.

Since the distribution of childhood cancers according to the histological type and location might be very different from what is observed in adults, cancer cases are described according to the International Classification of Disease-Oncology, third edition (ICDO-3) and grouped further using the International Classification of Childhood Cancer-third version (ICCC3) ${ }^{26}$ For patients diagnosed with multiple cancers during the follow-up, only the first occurring cancer was considered, except for nonmelanoma skin cancers.

\section{Statistical analysis}

The cohort characteristics were described as counts, proportions, means (with the SD) or median (with the IQR).

We conducted external comparisons using standardised incidence ratios (SIR) calculated as the ratio of the number of observed cases in the cohort to the number of expected cases based on the national cancer incidence rates provided by the RNCE. ${ }^{25}$ The SIRs were standardised by age $(0-1,1-5,5-10$ and $10-15)$, calendar year (2000-2005, 2005-2010 and 2010-2015), and by gender (male and female). Breslow and Day's approximation ${ }^{28}$ was used to estimate 95\% CI for the SIRs. The SIRs were calculated for five groups of cancer: all-cancer (including all childhood cancer types ICCC3: I-XII), leukaemia (ICCC3: Ia, Ib, Id, Ie), lymphoma (ICCC3: IIa-IIc), CNS tumours (ICCC3: IIIb, IIIc, IIIe, IIIf) and solid cancers excluding CNS tumours (ICCC3: IV, VI, VIII -XII).

In order to consider incident cancers possibly associated with CC exposure, we conducted sensitivity analyses in which a minimal exclusion period of 2 and 5 years between the first exposure and the cancer onset was applied by excluding respectively, patients who were diagnosed with a cancer within 2 and 5 years after the first CC procedure. The SIRs were also computed according to the number of procedures undergone $(1,2$ and 3 or 
Table 1 Description of the COCCINELLE cohort, 20002015

\begin{tabular}{lcc}
\hline & $\begin{array}{l}\text { Patients with } \\
\text { cancer } \\
\mathbf{n}=59\end{array}$ & $\begin{array}{l}\text { Patients without } \\
\text { cancer } \\
\mathbf{n}=17045\end{array}$ \\
\hline Demographics & $34(57.6)$ & $8702(51.1)$ \\
\hline Male, N (\%) & $2.6(9.9)$ & $2.2(7.4)$ \\
\hline $\begin{array}{l}\text { Median age (in year) } \\
\text { at first CC procedure } \\
\text { (IQR) }\end{array}$ & & \\
\hline $\begin{array}{l}\text { Median age (in year) } \\
\text { at exit (IQR) }\end{array}$ & $7.4(10.4)$ & $10.9(9.3)$ \\
\hline $\begin{array}{l}\text { Age at first CC } \\
\text { procedure, N (\%) }\end{array}$ & & \\
\hline$<1$ year & $24(40.7)$ & $6589(38.7)$ \\
\hline 1-5 years & $12(20.3)$ & $4206(24.7)$ \\
\hline 5-10 years & $8(13.6)$ & $3216(18.9)$ \\
\hline 10-15 years & $15(25.4)$ & $3034(17.8)$ \\
\hline Birth period, N (\%) & & $1095(6.4)$ \\
\hline (1980, 1990) & $2(3.4)$ & $484(2.8)$ \\
\hline (1990, 2000) & $20(33.9)$ & $4273(25.1)$ \\
\hline (2000, 2010) & $31(52.5)$ & $9511(55.8)$ \\
\hline (2010, 2013) & $6(10.2)$ & $2777(16.3)$ \\
\hline Number of CC procedures received by children, N (\%) \\
\hline 1 procedure & $44(74.6)$ & $13929(81.7)$ \\
\hline 2 procedures & $7(11.9)$ & $2021(11.9)$ \\
\hline 3 procedures & $8(13.6)$ & \\
\hline
\end{tabular}

CC, cardiac catheterisation; IQR, Interquartile range.

more) and a trend test was performed. SIR analyses were performed in R (R Foundation for Statistical Computing, Vienna, Austria) using the package Epi for the personyears computation and the package popEpi. ${ }^{29}$ The statistical significance was defined by $\mathrm{p}<0.05$.

\section{RESULTS}

\section{Characteristics of the study population}

The whole cohort consisted of 17104 subjects, 51\% of whom were males. The median duration of follow-up was 5.9 years (IQR 6.4 years), accounting for a total of 110335 person-years. Children younger than 1 year at their first CC represented $38.7 \%$ of the whole cohort. The median age at exit from the cohort was 10.8 years (IQR 9.3 years). The characteristics of the study patients are described in table 1 .

A total of $22227 \mathrm{CC}$ procedures were recorded in the cohort (table 2). The number of procedures received by the patients ranged from 1 to 14 ; about $82 \%$ of the study subjects received only one procedure. Diagnostic procedures represented $8931(40.2 \%)$ of all procedures performed, whereas therapeutic procedures represented
Table 2 Description of the cardiac catheterisation procedures received in the COCCINELLE cohort

\begin{tabular}{|c|c|c|}
\hline & Total & $(\%)$ \\
\hline \multicolumn{3}{|l|}{ Category of procedures } \\
\hline Therapeutic & 13296 & 59.8 \\
\hline Diagnostic & 8931 & 40.2 \\
\hline Total & 22227 & 100 \\
\hline \multicolumn{3}{|l|}{ Most frequent families of procedures } \\
\hline $\begin{array}{l}\text { Diagnostic cardiac catheterisation } \\
\text { without angiography* }\end{array}$ & 3868 & 17.4 \\
\hline Patent ductus arteriosus closure & 3046 & 13.7 \\
\hline Pulmonary valvuloplasty & 2052 & 9.2 \\
\hline Atrial septal defect closure & 1741 & 7.8 \\
\hline Right and left heart angiography* & 1466 & 6.6 \\
\hline Left heart angiography* & 1313 & 5.9 \\
\hline $\begin{array}{l}\text { Pulmonary artery dilatation or } \\
\text { stenting }\end{array}$ & 1310 & 5.9 \\
\hline Atrial septostomy & 1208 & 5.4 \\
\hline Electrophysiology procedures & 1165 & 5.2 \\
\hline Right heart angiography* & 1066 & 4.8 \\
\hline Other procedures & 3992 & 17.9 \\
\hline
\end{tabular}

${ }^{*}$ Diagnostic procedures.

13296 (59.8\%) (table 2). Among therapeutic procedures, the most frequent ones were patent ductus arteriosus closure (13.7\%), pulmonary valvuloplasty $(9.2 \%)$, atrial septal defect closure $(7.8 \%)$ and pulmonary artery dilatation or stenting $(5.9 \%)$.

\section{Findings to date}

Fifty-nine cancer cases were recorded from 2000 to 2015, among them $34(57.6 \%)$ occurred in males. The median age at cancer diagnosis was 7.4 years (IQR 10.4 years). The cancer types are described in table 3 . The number of procedures per subject was not different between the cancer cases and the non-cancer patients. Thirty-four out of 59 cancers were diagnosed at least 2 years after the first CC procedures which count $13(38.2 \%)$ lymphomas, 7 $(20.6 \%)$ leukaemia and $14(41.2 \%)$ solid cancers. After a 5-year exclusion period, 15 out of 59 cancer cases were observed with $7(46.7 \%)$ lymphomas, 2 (13.3\%) leukaemia and $6(40 \%)$ solid cancers.

The results of the analyses comparing cancer incidence in the cohort with that of the general population are presented in table 4 . The SIRs were increased for all-cancer (SIR=3.8, 95\% CI: 2.9 to 4.9), leukaemia ( $\mathrm{SIR}=3.3,95 \%$ CI: 2.0 to 5.4 ), lymphoma $(\mathrm{SIR}=14.9$, 95\% CI: 9.9 to 22.5 ) and solid cancers excluding CNS tumours (SIR=3.3, 95\% CI: 2.0 to 5.5 ) compared with the general population. In sensitivity analyses, after exclusion of cases diagnosed within the first 2 years after exposure to the first CC examination, SIRs were increased for all-cancer (SIR=3.4, 95\% CI: 2.4 to 4.7 ), 
Table 3 Description of the cancers that occurred in the COCCINELLE cohort from 2000 to 2015

\begin{tabular}{|c|c|c|c|}
\hline Cancer type & $\begin{array}{l}\text { All period } \\
\text { N (\%) }\end{array}$ & $\begin{array}{l}\text { After a 2-year exclusion* } \\
\text { N (\%) }\end{array}$ & $\begin{array}{l}\text { After a 5-year exclusion* } \\
\text { N (\%) }\end{array}$ \\
\hline $\begin{array}{l}\text { Leukaemia } \\
\text { ICCC3: la, Ib, Id, le }\end{array}$ & 15 (25.4) & 7 (20.6) & 2 (13.3) \\
\hline $\begin{array}{l}\text { Lymphoma } \\
\text { ICCC3: Ila-Ilc }\end{array}$ & $23(39.0)$ & $13(38.2)$ & 7 (46.7) \\
\hline $\begin{array}{l}\text { Central nervous system } \\
\text { ICCC3: IIIb, IIIc, IIle, IIIf }\end{array}$ & $6(10.2)$ & $5(14.7)$ & $1(6.7)$ \\
\hline $\begin{array}{l}\text { Neuroblastoma and other peripheral nervous cell } \\
\text { tumours ICCC3: IVa, IVb }\end{array}$ & $1(1.7)$ & $1(2.9)$ & $1(6.7)$ \\
\hline $\begin{array}{l}\text { Renal tumours } \\
\text { ICCC3: Vla, VIb }\end{array}$ & $4(6.8)$ & $3(8.8)$ & - \\
\hline $\begin{array}{l}\text { Malignant bone tumours } \\
\text { ICCC3: VIII }\end{array}$ & $1(1.7)$ & - & - \\
\hline $\begin{array}{l}\text { Germ cell tumours } \\
\text { ICCC } 3: X\end{array}$ & $2(3.4)$ & $1(2.9)$ & - \\
\hline $\begin{array}{l}\text { Other malignant epithelial neoplasms } \\
\text { ICCC3: XI }\end{array}$ & $2(3.4)$ & $1(2.9)$ & $1(6.7)$ \\
\hline $\begin{array}{l}\text { Other and unspecified malignant neoplasms } \\
\text { ICCC3: XII }\end{array}$ & $1(1.7)$ & $1(2.9)$ & $1(6.7)$ \\
\hline All-cancer & 59 (100) & 34 (100) & 15 (100) \\
\hline
\end{tabular}

*2-year and 5-year exclusion: exclusion of all-cancer cases diagnosed, respectively, within 2 or 5 years after the first CC procedure. ICCC3, International Classification of Childhood Cancer-third version ${ }^{25}$.

leukaemia (SIR=2.3, 95\% CI: 1.1 to 4.9 ), lymphoma ( $\mathrm{SIR}=10.8,95 \%$ CI: 6.3 to 18.7 ) and solid cancers excluding CNS tumours ( $\mathrm{SIR}=3.4,95 \%$ CI: 1.8 to 6.5 ). When considering a 5-year exclusion period, increased SIRs were observed for all-cancer ( $\mathrm{SIR}=3.3,95 \% \mathrm{CI}$ : 2.0 to 5.4 ), lymphoma ( $\mathrm{SIR}=9.5,95 \% \mathrm{CI}: 4.5$ to 20.0 ) and solid cancers excluding CNS tumours ( $\mathrm{SIR}=4.3$, 95\% CI: 1.8 to 10.2$)$. SIRs were increased whatever the number of procedure received (1,2 and 3 or more) with higher SIR for patients receiving three or more procedures $(\mathrm{SIR}=6.1,95 \% \mathrm{CI}: 3.0$ to 12.1$)$ compare to those receiving one procedure ( $\mathrm{SIR}=3.7,95 \% \mathrm{CI}: 2.7$ to 4.9). However, the p-value for trend in SIRs according to the number of procedures undergone (1, 2 and 3 or more) was not statistically significant, $\mathrm{p}$-value $=0.2$ (table 4).

\section{DISCUSSION}

\section{Main findings}

This first analysis of the COCCINELLE cohort shows a higher incidence of all-cancer, leukaemia, lymphoma and other solid cancer (excluding CNS tumours) in the cohort compared with the general population. The SIRs increased non-significantly with the increasing number of procedures received in childhood. In a sensitivity analysis in which all cases occurring during the first 2-years and 5-years were excluded, the SIRs remained significantly increased for all-cancer, lymphoma and solid cancer excluding CNS tumours. As about $82 \%$ of the cohort received only one procedure, these exclusion periods were used as a surrogate to the latency period, that is, the minimal delay between exposure and cancer incidence to be considered.

The results from the current study are consistent with the two previous studies that reported increased cancer incidence following paediatric CC for $\mathrm{CHD}^{1222}$ compared with the general population. Modan et $a l^{12}$ observed a SIR of 2.3 (95\% CI: 1.2 to 4.1 ) based on the follow-up of 674 children between 1950 and 1970 in Israel and Harbron et $a l^{22}$ reported higher incidence rates for all-cancer ( $\mathrm{SIR}=2.32 ; 95 \%$ CI: 1.65 to 3.17 ), lymphoma ( $\mathrm{SIR}=8.34$; 95\% CI: 5.22, to 12.61), and leukaemia ( $\mathrm{SIR}=2.11 ; 95 \%$ CI: 0.82 to 4.42 ) in a cohort of 11270 children exposed when aged $\leq 22$ years. On the contrary, a study based on the follow-up of 3915 children and young adults exposed to CC before the age of 18 between 1946 and 1968 in Canada did not report any significant increase in cancer incidence, with a SIR of $0.75(90 \%$ CI: 0.4 to 1.2$){ }^{23}$ In adult population, an increased SIR for all-cancer was also reported from a study on patients who had undergone CC for CHD at adulthood. ${ }^{30}$

CT and CG procedures both deliver X-ray radiation. Recent studies reported radiation doses delivered by CT ranging from 8 to 12 milliGray (mGy) to the red 
Table 4 Standardised incidence ratio (SIR) for cancers in the COCCINELLE cohort

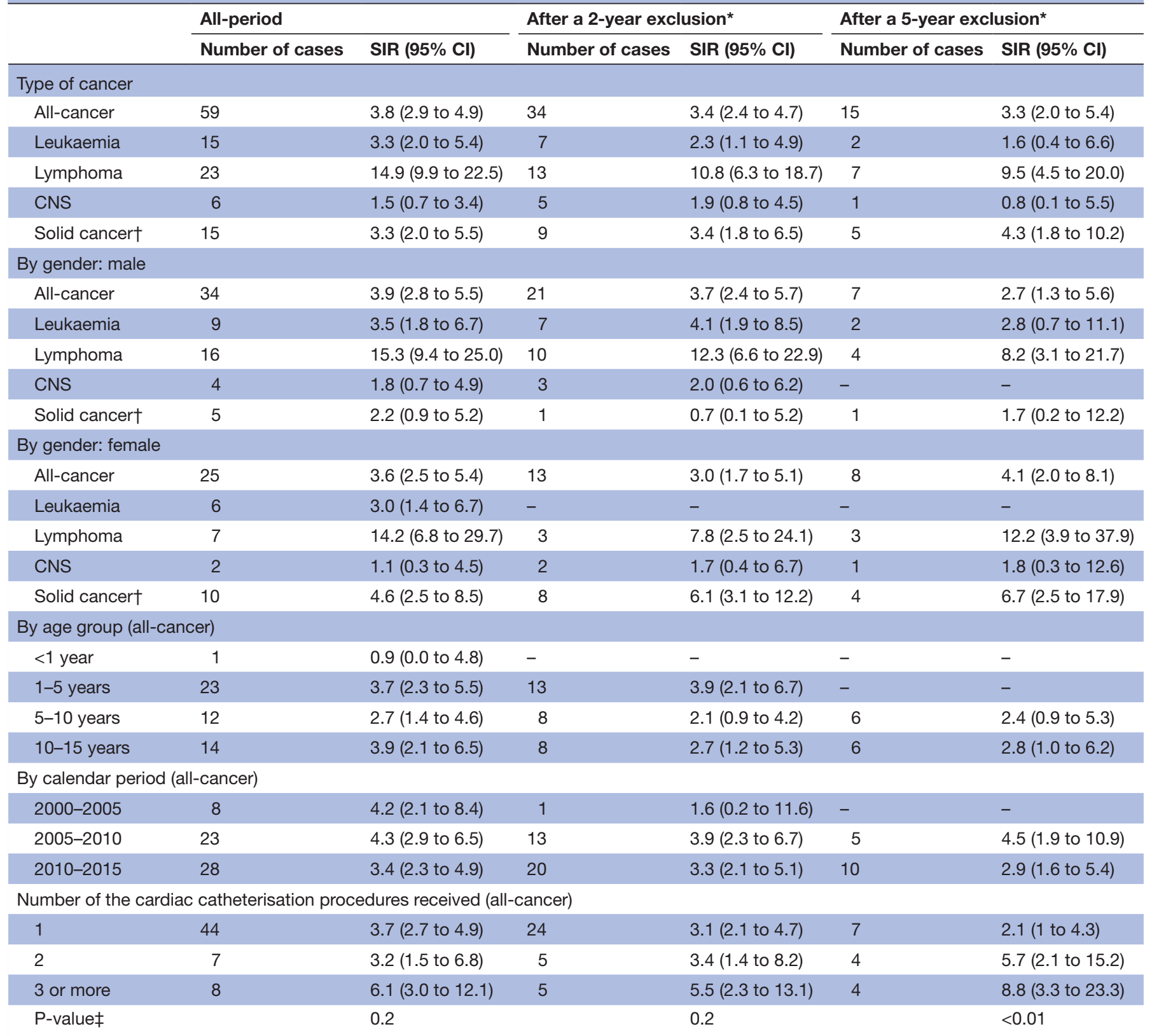

*2-year and 5-year exclusion: exclusion of all-cancer cases diagnosed, respectively, within 2 or 5 years after the first CC procedure.

†Solid cancer excluding central nervous system tumours.

$\ddagger$-value for trends.

CNS, central nervous system tumours; SIR, standardised incidence ratio.

bone marrow, ${ }^{31-34}$ a range of doses consistent to the mean dose of $8.8 \mathrm{mGy}$ to the red bone marrow reported from a recent CC study. ${ }^{22}$ As cumulative doses due to CT in childhood are in the range of those delivered by CC procedures, the estimated SIRs in our cohort can be compared with those from recently published CT studies. ${ }^{32-35}$ Findings from the current study are consistent with results from a nationwide retrospective cohort of 168394 children who received one or more CT in Dutch hospitals between 1979 and 2012, when aged $<18$ years: ${ }^{34}$ the SIRs were 1.47 (95\% CI: 1.34 to 1.61) for all-cancer, 1.39 (95\% CI: 1.13 to 1.70 ) for haemato-lymphoproliferative disorders and $2.05(95 \%$ CI: 1.48 to 2.83) for CNS tumours after applying a 5-year latency period. In a German study on 39184 children younger than 15 years who received CT between 1980 and 2010, Krille $e t a l^{3233}$ reported significant increased SIRs for all-cancer (SIR=1.82, 95\% CI: 1.29 to 2.50), and lymphoma ( $\mathrm{SIR}=2.96,95 \% \mathrm{CI}: 1.42$ to 5.45 ).

CHD patients usually require ongoing care to monitor their condition that may result in repeated exposure to LDIR $^{35}$ 7-9 and may lead to hig h cumulative doses. In the current study, the cumulative number of procedure received (1, 2 and $\geq 3$ procedures) is used as a surrogate to 
the cumulative individual doses. A significant increased SIR was observed whatever the number of CC procedures performed, but a slight non-significant positive trend was observed in the SIRs according to the increasing number of procedures received ( $\mathrm{SIR}=3.7,95 \%$ CI: 2.7 to 4.9 for one procedure, SIR $=3.2,95 \%$ CI: 1.5 to 6.8 for 2 procedures and SIR=6.1, 95\% CI: 3.0 to 12.1 for $\geq 3$ procedures; $\mathrm{p}$-value for trends=0.2). Cohen $e$ t $a \vec{l}^{30}$ used the cumulative number of procedure performed to estimate the risk of cancer after exposure to LDIR in adult patients and shown that the cumulative number of procedures and the cumulative effective dose could lead to similar results. In the current study, however, since no dose assessment and no dose-response analyses are yet available to explain the increased SIRs according to the cumulative number of procedures received, this result should be interpreted with caution. An individual dose reconstruction is currently underway to estimate the cumulative organ doses for each of the cohort members, including the contribution of doses from CTs and other medical diagnostic radiation procedures. A dose-response analysis will then be performed to confirm or not these first results.

\section{Strengths and limitations}

The COCCINELLE cohort is the first study in France to assess cancer risk in 17,104 CHD patients who undergone CC in childhood. The study has access to national well-handled registries which have almost an exhaustive coverage of the general population. The sample of CHD patient included in the cohort is representative of the paediatric CHD patients since the major paediatric departments performing CC in mainland France agreed to participate to the study and contributed actively. However, several limitations should be mentioned.

The SIR analyses did not include any information on the dose received during the CC procedures and the results should be interpreted consequently. Doses estimates are currently underway to provide with accurate dosimetry data for each patient in the study and cumulative organ doses will be used in the dose-response analyses. In addition, CHD paediatric patients could undergo other diagnostic LDIR procedures such as CT which deliver dose in the same range as CC, nuclear medicines and conventional radiographies. The more patients have received CC, the more they are susceptible to be exposed to other diagnostic medical LDIR. It is important to consider these various sources of exposure since they can contribute significantly to the overall cumulative organ dose. This additional information on other medical exposure would be retrieved from the National Health Data System. Further analyses in the cohort will include doses from CC and other medical diagnosis procedures in the dose-response analyses. The individual dose reconstruction is intended for procedures performed in the cohort, from 2000 to 2013. However, single doses delivered per examination are continuously decreasing due to advances in technologies, protocol improvements and awareness of cardiologists. Therefore, the dose estimates will not reflect the current dose reduction practices in cardiology departments and this weakness is inherent to all retrospective epidemiology studies. Nevertheless, epidemiology studies are still relevant for decision making and radioprotection purposes.

Other limitation from the first results of the SIR analyses is the use of the general population as reference group. An increased risk of cancer in CHD patients compared with the general population has already been reported. ${ }^{13}$ Common etiologic factors in CHD patients could be suspected ${ }^{11}{ }^{21}$ as gene mutations in embryogenesis related to birth defects and cancer development. ${ }^{36}$ Post-transplants are also known to present higher rate of cancer due to the use of immunosuppression drugs. ${ }^{37}$ In the UK study on cancer risk after CC in childhood, 509 out of 11270 individuals had received a transplanted organ with 26 malignancies occurring among these transplanted patients. The authors reported that all of the lymphoma cases observed in the cohort came from transplanted subjects. Furthermore, censoring these transplant subjects decreased the SIR for all-cancer from 2.32 (95\% CI: 1.65 to 3.17 ) to 0.90 (95\% CI: 0.49 to 1.49$).{ }^{22}$ Transplantation status and any other cancer predisposing factors are not considered in the SIRs analysis and the increased SIRs reported in the present study might be confounded with a potential effect of underlying cancer predisposing factors such as Down syndrome, Noonan syndrome or severe combined immune deficiency.

Indication bias and reverse causation bias can be suspected when cancer predisposing factors or early symptoms of undetected cancer are the indication of the examination. In the COCCINELLE cohort study, reverse causation bias can be ruled out as the indication of CC is always the CHD. However, indication bias should be studied since medical conditions associated with cancer risk predisposition could also be associated with exposure to LDIR diagnostic procedures. Then, it will be crucial to take into account individual information on cancer risk predisposition in the ongoing main analyses. Due to the lack of a national registry on transplantation or genetic syndromes in France, the COCCINELLE cohort will use information from the National Health Data System, which are complete enough to retrieve patients with predisposing factors to cancer. ${ }^{38}$

The study will take into account as much as possible the main factors that could be associated with the studied outcome, as the genetic or hereditary disorders and immunodeficiency factors associated with cancer. In addition, children with history of cancer prior to the CC examination were excluded from the cohort to avoid potential effect of radiotherapy or chemotherapy on a subsequent cancer. However, our study was not designed to directly assess the effect of factors such as obesity, socioeconomic status, lifestyle and environmental factors in the risk estimate models since these data could not be retrieved directly from medical record databases. However, major known factors associated with cancer risks such as smoking and/or alcohol consumption are unlikely to impact the risk estimates as the studied population includes only children with a follow-up limited to 18 years in this analysis. 
A strength of the study is to be able to take into account some other cancer risk factors such as exposure to other medical diagnostic LDIR such as CT, nuclear medicine and conventional radiography that will be retrieved from the National Health Data System.

The death rate in the cohort is currently $6.5 \%$ for 803 deaths registered in patients for whom this information is available. Investigators had reported an increased mortality rates among CHD population, ${ }^{39}$ suggesting that some subjects might die from the underlying condition (ie, cardiac dysfunction) before developing cancer. Therefore, competitive risk should be considered in the ongoing analyses to take into account the risk of death before the studied outcome, that is, cancer. This was observed in the French cohort study on CTs, where the early increased mortality in patients with predisposing factors to cancer leads to decreased risks of radiation associated leukaemia and CNS tumour compared with the increased risk observed in patients without predisposing factors to cancer. ${ }^{31}$

The number of patients lost to follow-up is currently low in the cohort since children with CHD are closely followed in cardiology departments involved in this study for the monitoring of their conditions. They can be retrieved from medical records or from the National Health Data System after 2006; however, we are not able to follow patients, who have emigrated, been diagnosed or treated outside France borders. The follow-up of our population is currently limited to the age of 18 years, due to the lack of a nationwide cancer registry for adults. However, the building of a national cohort of cancer patients since 2011 by the French National Cancer Institute (Institut National du Cancer) based on the National Health Data System will provide a very useful tool to follow the incidence of cancer in our cohort at adult age. ${ }^{40}$

\section{Perspectives and collaboration}

Overall, the future plans for the cohort analysis include an individual dose reconstruction and the assessment of the dose-response relationship in regard of the cumulative radiation dose received by each patient. Furthermore, potential impact of confounding factors such as age at exposure, gender and attained age will be assessed. The assessment of potential bias as cancer predisposing factors or additional doses from other medical diagnostic procedure will be possible, thanks to the information retrieved from the National Health Data System. We plan also to link our cohort with the ongoing national cohort of cancer cases set up by the French National Cancer Institute since 2011, based on data from the National Health Data System, ${ }^{40}$ which will allow the follow-up of the cohort patients beyond the age of 18 years old.

The number of cancer cases reported in the current study is small, due to a short duration of follow-up and low cancer incidence rates. A way to overcome this limitation and increase the statistical power of the study is to conduct combined analyses of several similar studies. The COCCINELLE cohort is contributing to the HARMONIC (for Health effects of cArdiac fluoRoscopy and MOderN
radIotherapy in paediatrICs) project ${ }^{41}$ that pools together seven large national European cohorts (Belgium, France, Italy, Germany, Norway, Spain and the UK), to increase the statistical power of the analyses. In a few years, HARMONIC will provide information on the risk of cancer associated with exposure to diagnostic radiation received during childhood with a precision that could not be achieved with individual national studies.

The COCCINELLE study data are not freely available because of ethical and data protection constraints. However, we welcome inputs from researchers on collaborative projects that will involve the study data. Proposals for possible collaborations in further analyses of the data should be addressed to Dr Estelle Rage.

\section{Author affiliations}

${ }^{1}$ PSE-SANTE/SESANE/Laboratory of Epidemiology, Institute for Radiological Protection and Nuclear Safety (IRSN), Fontenay-aux-Roses, Île-de-France, France ${ }^{2}$ Department of Congenital and Pediatric Cardiology, Necker-Sick Children University Hospital, M3C-Necker, Université de Paris, Paris, France

${ }^{3}$ Paediatric and Congenital Cardiac Surgery Department, M3C Marie-Lannelongue Hospital, National Reference Centre, Groupe Hospitalier Saint-Joseph, Paris Saclay University, Plessis-Robinson, France

${ }^{4}$ PSE-SANTE/SER/UEM, Institute for Radiological Protection and Nuclear Safety (IRSN), Fontenay-aux-Roses, Île-de-France, France

${ }^{5}$ AMAREXIA, Paris, France

${ }^{6}$ Cardiology and Vascular Department, Hopital Gabriel Montpied, Clermont-Ferrand, France

${ }^{7}$ Paediatric and Congential Cardiology Department, Hôpital Cardiologique Louis Pradel, Hospices Civils de Lyon, Université Claude Bernard Lyon 1, Lyon, France ${ }^{8}$ Cardiopédiatrie, Hôpital couple enfant, CHU Grenoble Alpes, Grenoble cedex 9 , France, Grenoble, France

${ }^{9}$ Service de Cardiologie Infantile et Congénitale, Institut Cœur Poumon, Lille Cedex, Lille, France

${ }^{10}$ Clinique Cardiologique et des Maladies Vasculaires, CIC 1413, Institut du Thorax, Cardiopédiatrie, CHU Nantes, INSERM, Nantes Université, Nantes, France

${ }^{11}$ Unit of Cardiopediatrics, University Hospital of Strasbourg, Strasbourg, France

${ }^{12}$ Pediatric and Congenital Cardiology, Children's Hospital and INSERM U1048, I2MC, Institut des Maladies Métaboliques et Cardiovasculaires, Université de Toulouse, Toulouse, France

${ }^{13}$ Institut des Cardiopathies Congénitales, CHRU Tours, Tours, France

${ }^{14}$ Unité de cardiologie pédiatrique et congénitale, American Memorial Hospital, CHU de Reims, 47 rue Cognacq-Jay, Reims Cedex, Reims, France

${ }^{15}$ Cardiologie pédiatrique et congénitale, Timone enfants, AP-HM et INSERM 1251 , Aix-Marseille Université, Marseille, France

${ }^{16}$ Institut Cardiovasculaire Paris Sud, Institut Hospitalier Jacques-Cartier, Massy, France

${ }^{17}$ Department of Pediatric and Adult Congenital Cardiology, Bordeaux University Hospital (CHU), Bordeaux, France

Acknowledgements We gratefully thank all the staff members of the participating centers for their contribution to this project, in particular we warmly thank $\mathrm{Pr}$ Jérôme Petit (Cardiology department, Hôpital Marie Lannelongue, Le Plessis Robinson), Dr Hélène Bouvaist, Dr Isabelle Pin, Dr Julia Rousseau and Mrs Caroline Tournegros (Cardiopédiatrie, hôpital couple enfant, CHU Grenoble Alpes), Dr Nadir Benbrik, Dr Bénédicte Romefort, Dr Laurianne Le Gloan and Dr Karine Warin Fresse (CHU Nantes, Clinique Cardiologique et des Maladies Vasculaires, Nantes), Dr Zakaria Jalal and Dr Xavier Iriart (Department of Paediatric and Adult Congenital Cardiology, Bordeaux University Hospital (CHU), Pessac), Dr Julie Haesebaert (Hospices Civils de Lyon, Pôle de Santé Publique-Service de Recherche et d'Epidémiologie Cliniques, Lyon), Pr Alain Chantepie (Institut des Cardiopathies Congénitales, CHRU Tours), Dr Ivan Bouzguenda (Institut Hospitalier Jacques-Cartier, Massy), Dr Céline Gronier (Institut cardiovasculaire de Strasbourg - Clinique Rhena), Mrs Brigitte Girodon (M3C-Necker, Hôpital universitaire Necker-Enfants malades), Pr Philippe Acar (Pediatric and Congenital Cardiology, Children's Hospital, University of Toulouse), Pr Jean-René Lusson, Mr Pierre-Emmanuel Dine, Mr Joël Guersen and Mr Florian Magnier (Pôle Imagerie Diagnostique et Radiologie Interventionnelle, 
CHU Clermont Ferrand), Dr Ali Houeijeh and Mr Jean-Benoît Baudelet (Service de Cardiologie Infantile et Congénitale, Institut Cœur Poumon, Lille), Dr Angelo Livolsi, Dr Selim Saad (Unit of Cardiopediatrics, University Hospital of Strasbourg, Strasbourg), Mrs Christiane Leleu (Unité de cardiologie pédiatrique et congénitale, American Memorial Hospital, CHU de Reims). This report makes use of data obtained from the French national childhood cancer registry and we acknowledge Dr Brigitte Lacour for her help and her support.

Contributors $\mathrm{M}-\mathrm{OB}, \mathrm{ER}$ and $\mathrm{KL}$ lead the project at national level, raised the funding, established the cohort and provided intellectual inputs to the manuscript. KDA and TF were involved in data analysis, data presentation and drafted the manuscript. SM-M, SH, SDr, SC and DB contributed to the implementation of the project and to the conception of this article. CD, SD-F, SDo, FG, PG, PH, CK, BL, PM, $\mathrm{CO}, \mathrm{J}-\mathrm{FP}$ and J-BT were the local investigators of the project. They contributed to the study design and critically revised the manuscript for important intellectual content. All authors critically revised the manuscript and approved the final version.

Funding This work had received funding from La Ligue contre le cancer (GB/MA/ $\mathrm{CD} / \mathrm{BC}$ 11264) and the French National Cancer Institute (INCa) (CFB/SZ-07/06-020).

Competing interests None declared.

Patient consent for publication Not required.

Ethics approval The study received ethical approval from the French national data protection commission (Commission Nationale de l'Informatique et des Libertés), deliberation N²016-067 of 13 August 2016.

Provenance and peer review Not commissioned; externally peer reviewed.

Data availability statement Data are available upon reasonable request. Data may be obtained from a third party and are not publicly available. All data from the COCCINELLE study are deposited at the Laboratory of Epidemiology at French Institute for Radiological Protection and Nuclear Safety (IRSN), BP 17, 92262 Fontenay-aux-Roses, France. The COCCINELLE study data sharing is subject to ethical and data protection constraints. Interested researchers can approach ER principal investigator (estelle.rage@irsn.fr) for sharing COCCINELLE data as part of collaborative research projects (if not overlapping with ongoing research projects, and subject to a Data Use Agreement).

Supplemental material This content has been supplied by the author(s). It has not been vetted by BMJ Publishing Group Limited (BMJ) and may not have been peer-reviewed. Any opinions or recommendations discussed are solely those of the author(s) and are not endorsed by BMJ. BMJ disclaims all liability and responsibility arising from any reliance placed on the content. Where the content includes any translated material, BMJ does not warrant the accuracy and reliability of the translations (including but not limited to local regulations, clinical guidelines, terminology, drug names and drug dosages), and is not responsible for any error and/or omissions arising from translation and adaptation or otherwise.

Open access This is an open access article distributed in accordance with the Creative Commons Attribution Non Commercial (CC BY-NC 4.0) license, which permits others to distribute, remix, adapt, build upon this work non-commercially, and license their derivative works on different terms, provided the original work is properly cited, appropriate credit is given, any changes made indicated, and the use is non-commercial. See: http://creativecommons.org/licenses/by-nc/4.0/.

\section{ORCID iDs}

Kossi Dovene Abalo http://orcid.org/0000-0001-5064-0215

Serge Dreuil http://orcid.org/0000-0002-6160-0670

\section{REFERENCES}

1 Lucas FL, DeLorenzo MA, Siewers AE, et al. Temporal trends in the utilization of diagnostic testing and treatments for cardiovascular disease in the United States, 1993-2001. Circulation 2006;113:374-9.

2 Yang JC-T, Lin M-T, Jaw F-S, et al. Trends in the utilization of computed tomography and cardiac catheterization among children with congenital heart disease. J Formos Med Assoc 2015:114:1061-8.

3 Beauséjour Ladouceur V, Lawler PR, Gurvitz M, et al. Exposure to low-dose ionizing radiation from cardiac procedures in patients with congenital heart disease: 15-year data from a population-based longitudinal cohort. Circulation 2016;133:12-20.

4 Andreassi MG, Picano E. Reduction of radiation to children: our responsibility to change. Circulation 2014;130:135-7.

5 Johnson JN, Hornik CP, Li JS, et al. Cumulative radiation exposure and cancer risk estimation in children with heart disease. Circulation 2014;130:161-7.
6 Onnasch DGW, Schröder FK, Fischer G, et al. Diagnostic reference levels and effective dose in paediatric cardiac catheterization. $\mathrm{Br} J$ Radiol 2007;80:177-85.

7 Ait-Ali L, Andreassi MG, Foffa I, et al. Cumulative patient effective dose and acute radiation-induced chromosomal DNA damage in children with congenital heart disease. Heart 2010;96:269-74.

8 Glatz AC, Purrington KS, Klinger A, et al. Cumulative exposure to medical radiation for children requiring surgery for congenital heart disease. J Pediatr 2014:164:789-94.

9 Hill KD, Frush DP, Han BK, et al. Radiation safety in children with congenital and acquired heart disease: a scientific position statement on multimodality dose optimization from the image gently alliance. JACC Cardiovasc Imaging 2017;10:797-818.

10 Gurvitz M, lonescu-Ittu R, Guo L, et al. Prevalence of cancer in adults with congenital heart disease compared with the general population. Am J Cardiol 2016;118:1742-50.

11 Lee Y-S, Chen Y-T, Jeng M-J, et al. The risk of cancer in patients with congenital heart disease: a nationwide population-based cohort study in Taiwan. PLoS One 2015;10:e0116844.

12 Modan B, Keinan L, Blumstein T, et al. Cancer following cardiac catheterization in childhood. Int J Epidemiol 2000;29:424-8.

13 Cohen S, Gurvitz MZ, Beauséjour-Ladouceur V, et al. Cancer risk in congenital heart Disease-What is the evidence? Can J Cardiol 2019;35:1750-61.

14 Little MP. Cancer and non-cancer effects in Japanese atomic bomb survivors. J Radiol Prot 2009;29:A43.

15 Little MP. Leukaemia following childhood radiation exposure in the Japanese atomic bomb survivors and in medically exposed groups. Radiat Prot Dosimetry 2008;132:156-65.

16 Little MP, Wakeford R, Borrego D, et al. Leukaemia and myeloid malignancy among people exposed to low doses (<100 mSv) of ionising radiation during childhood: a pooled analysis of nine historical cohort studies. Lancet Haematol 2018;5:e346-58.

17 Fazel R, Krumholz HM, Wang Y, et al. Exposure to low-dose ionizing radiation from medical imaging procedures. $N$ Engl J Med 2009;361:849-57.

18 UNSCEAR: United Nations Scientific Committee on the Effects of Atomic Radiation. Sources, effects and risks of ionizing radiation. volume II. scientific Annex B: effects of radiation exposure of children. New York United Nations; 2013.

19 Van Cleave J, Gortmaker SL, Perrin JM. Dynamics of obesity and chronic health conditions among children and youth. JAMA 2010;303:623-30.

20 Bjørge T, Cnattingius S, Lie RT, et al. Cancer risk in children with birth defects and in their families: a population based cohort study of 5.2 million children from Norway and Sweden. Cancer Epidemiol Biomarkers Prev 2008;17:500-6.

21 Fisher PG, Reynolds P, Von Behren J, et al. Cancer in children with nonchromosomal birth defects. J Pediatr 2012;160:978-83.

22 Harbron RW, Chapple C-L, O'Sullivan JJ, et al. Cancer incidence among children and young adults who have undergone X-ray guided cardiac catheterization procedures. Eur J Epidemiol 2018;33:393-401.

23 McLaughlin JR, Kreiger N, Sloan MP, et al. An historical cohort study of cardiac catheterization during childhood and the risk of cancer. Int J Epidemiol 1993;22:584-91.

24 Baysson H, Nkoumazok B, Barnaoui S, et al. Follow-Up of children exposed to ionising radiation from cardiac catheterisation: the Coccinelle study. Radiat Prot Dosimetry 2015;165:13-16.

25 Lacour B, Guyot-Goubin A, Guissou S, et al. Incidence of childhood cancer in France: national children cancer registries, 2000-2004. Eur $J$ Cancer Prev 2010;19:173-81.

26 Steliarova-Foucher E, Stiller C, Lacour B, et al. International classification of childhood cancer, third edition. Cancer 2005;103:1457-67.

27 RNCE. Taux d'incidence de 2010 2014, par groupe diagnostique et par tranche d'âge. Available: https://rnce.inserm.fr/index.php/fr/ statistiques/statistiques-d-incidence/taux-d-incidence-de-2010-a2014-par-groupe-diagnostique-et-par-tranche-d-age [Accessed 28 Jan 2020].

28 Breslow NE, Day NE. Statistical methods in cancer research volume II: the design and analysis of cohort studies. IARC Scientific Publication. IARC Scientific Publication No. 82, Lyon, France: International Agency for Research on Cancer, 1987.

29 Miettinen J, Rantanen M, Seppa K. popEpi: functions for epidemiological analysis using population data. $R$ package version $0.4 .8,2019$. Available: https://CRAN.R-project.org/package= popEpi

30 Cohen S, Liu A, Gurvitz M, et al. Exposure to low-dose ionizing radiation from cardiac procedures and malignancy risk in adults with congenital heart disease. Circulation 2018;137:1334-45. 
31 Journy N, Roué T, Cardis E, et al. Childhood CT scans and cancer risk: impact of predisposing factors for cancer on the risk estimates. J Radiol Prot 2016;36:N1.

32 Krille L, Dreger S, Schindel R, et al. Risk of cancer incidence before the age of 15 years after exposure to ionising radiation from computed tomography: results from a German cohort study. Radiat Environ Biophys 2015;54:1-12.

33 Krille L, Dreger S, Schindel R, et al. Erratum to: Risk of cancer incidence before the age of 15 years after exposure to ionising radiation from computed tomography: results from a German cohort study. Radiat Environ Biophys 2017;56:293-7.

34 Meulepas JM, Ronckers CM, Smets AMJB, et al. Radiation exposure from pediatric CT scans and subsequent cancer risk in the Netherlands. J Nat/ Cancer Inst 2019;111:256-63.

35 Abalo KD, Rage E, Leuraud K, et al. Early life ionizing radiation exposure and cancer risks: systematic review and meta-analysis. Pediatr Radiol 2021;51:1-12.
36 Narod SA, Hawkins MM, Robertson CM, et al. Congenital anomalies and childhood cancer in Great Britain. Am J Hum Genet 1997;60:474.

37 Grulich AE, van Leeuwen MT, Falster MO, et al. Incidence of cancers in people with HIV/AIDS compared with immunosuppressed transplant recipients: a meta-analysis. Lancet 2007;370:59-67.

38 Bernier M-O, Mezzarobba M, Maupu E, et al. [Role of French hospital claims databases from care units in epidemiological studies: the example of the "Cohorte Enfant Scanner" study]. Rev Epidemiol Sante Publique 2012;60:363-70.

39 Meberg A, Otterstad JE, Frøland G, et al. Outcome of congenital heart defects-a population-based study. Acta Paediatr 2000;89:1344-51.

40 Bousquet PJ, Lefeuvre D, Tuppin P, et al. Cancer care and public health policy evaluations in France: usefulness of the National cancer cohort. PLoS One 2018;13:e0206448.

41 Harmonic. Available: https://harmonicproject.eu/ [Accessed 20 Dec 2020]. 